\title{
Determination of VOCs in groundwater at an industrial contamination site using a homemade low-density polyethylene passive diffusion sampler
}

\author{
Xu Ma, Zhiqiang Tan, Long Pang, Jingfu Liu* \\ State Key Laboratory of Environmental Chemistry and Ecotoxicology, Research Center for Eco-Environmental Sciences, \\ Chinese Academy of Sciences, Beijing 100085, China
}

Received 25 February 2013; revised 16 April 2013; accepted 18 April 2013

\begin{abstract}
A home-made inexpensive passive diffusion bag (PDB) sampler, prepared by filling deionized water in low-density polyethylene (LDPE) tubes, was evaluated for volatile organic compounds (VOC) sampling in groundwater at industrial contamination sites. Impacts of environmentally relevant conditions on the sampling equilibration time and partitioning of VOCs between the sampler and the water sample were investigated. Sample salinity, agitation and temperature can influence the equilibration time, but generally sampling equilibration was obtained in 14 days under real field sampling of VOCs in groundwater. Both laboratory study and field testing in a contaminated site showed that the VOC concentrations in the developed sampler were equal to those in the water samples at equilibrium. Coupled with a purge and trap concentrator-gas chromatograph-mass spectrometer (P\&T-GC-MS), the developed PDB sampler provided a low-cost sampling device for routine monitoring of VOCs in groundwater in wells, with LODs in the range of 2.9-10 $\mu \mathrm{g} / \mathrm{L}$. The proposed PDB was applied to determine VOCs in groundwater at an industrial contamination site, and the present results agreed well with those determined using conventional pump-and-sample monitoring. All the studied 13 VOCs were tested in the four wells in the industrial contamination sites, with their concentrations in the range of $12-73660 \mu \mathrm{g} / \mathrm{L}$. In addition, while benzene and toluene were heavily contaminated up to a maximum concentration of $74000 \mu \mathrm{g} / \mathrm{L}$ and $6000 \mu \mathrm{g} / \mathrm{L}$, respectively, 1,2,3-trichlorobenzene and bromobenzene had relatively low contamination levels (below $25 \mu \mathrm{g} / \mathrm{L}$ ).
\end{abstract}

Key words: equilibration time; ground water; passive sampling; polyethylene diffusion bag; volatile organic compounds DOI: $10.1016 / \mathrm{S} 1001-0742(12) 60322-2$

\section{Introduction}

Long-term monitoring of volatile organic compounds (VOCs) in groundwater is of great importance in remediation of contaminated sites (Divine et al., 2005; Verreydt et al., 2010). Conventional sampling procedures like power-requiring purge-and-sample methods suffer from an unwanted distortion of the contaminant concentration owing to a change in the hydraulic flow field, and mass loss and therefore lower contaminant concentrations in the water samples due to the volatilization of analytes during the sampling processes (Martin et al., 2003; Mcleish et al., 2007). Therefore, passive diffusion bag (PDB) samplers prepared by filling deionized water in heat-sealed, lowdensity polyethylene (LDPE) lay-flat tubes were developed for sampling VOCs in groundwater (Vroblesky and Hyde, 1997; Vroblesky and Campbell, 2001). By deploying PDB in ground water, the VOCs of interest diffuse across the LDPE membrane according to the local concentration

\footnotetext{
* Corresponding author: E-mail: jfliu@ @rcees.ac.cn
}

gradient until the VOC concentration in the water phase of the sampler is equilibrated with the concentration outside the sampler. At equilibrium, usually after 2 to 14 days depending on the field conditions and the properties of VOCs, the VOC concentrations measured in the sampler are assumed to be equal to that of the groundwater at the deployment location (Vroblesky and Hyde, 1997).

In comparison with traditional sampling methods, the PDB is a viable alternative as it is disposable and relatively inexpensive (Ehlke et al., 2004). In addition, PDB provides the advantage of not requiring removal and disposal of large amounts of well water prior to sampling, and can be deployed in multilevels of a well to enhance the spatial resolution of assessment. Furthermore, PDB samples VOCs in groundwater without any auxiliary equipment such as a pump, which facilitates deployment in small diameter wells (Harter and Talozi, 2004). Despite the wide application of PDB in VOC monitoring in developed countries, the use of PDB in determination of VOCs in developing countries is very limited, mainly because the commercially 
available PDB samplers are relatively expensive.

In this present study, a homemade PDB was adopted to determine VOCs in groundwater at an industrial contamination site in Beijing. Parameters that might influence the equilibration time and partitioning of VOCs between the sampler and the ground water were evaluated. The VOC concentrations in ground water at four observation wells determined using the developed PDB sampler agreed well with those determined using conventional pump-andsample monitoring.

\section{Materials and methods}

\subsection{Reagents and solutions}

A mixed standard containing 13 kinds of VOCs was obtained from Supelco (Sigma-Aldrich, USA). The stock standard of VOCs $(2 \mathrm{mg} / \mathrm{mL})$ was prepared in methanol and stored at $4^{\circ} \mathrm{C}$ in the dark. Working solutions were prepared by sequential dilution of the standard solution with methanol. Ultrapure water $(18.2 \mathrm{M} \Omega \cdot \mathrm{cm})$ was prepared using a Milli-Q water purification system (Millipore, Bedford, USA).

\subsection{Preparation of PDB sampler}

The PDB samplers were prepared with a single layer of 20-mm width LDPE lay-flat tubing (Shenghe Membrane Company, Beijing, China). A $16 \mathrm{~cm}$ length of LDPE tubing with one heat-sealed end was filled with $20 \mathrm{~mL}$ of deionized water, and the open end of the tubing was sealed with a heat sealer (Shenghe Membrane Company, Beijing, China). The LDPE membrane had a thickness of $100 \mu \mathrm{m}$.

\subsection{Optimization of the sampling procedure}

The sampling procedure was optimized under laboratory conditions. A mixed standard solution containing $100 \mu \mathrm{g} / \mathrm{L}$ each of the VOCs was added to a $1000 \mathrm{~mL}$ gas-tight jar, and then a PDB sampler was deployed in it. After sampling for a prescribed time, the PDB samplers were recovered from the jars, and water from/out of the PDB samplers was transferred immediately to 40-mL Tekmar amber glass vials (EPA Method 524.2). The water in the vials was acidified with hydrochloric acid and capped, leaving no headspace. Immediately after, samples were placed inside a portable freezer and were analyzed for VOCs using a purge and trap (P\&T) concentrator coupled with GC-MS. All samples were analyzed within 7 days after collection to avoid sample losses during storage. Both diffusion samplers and ambient water in the jars were sampled in triplicate.

\subsection{Field sampling}

Three PDB samplers were installed, with a nylon monofilament line secured to the well surface casing, in each of the four groundwater monitoring wells at an industrial contamination site located in the southeast region of Chaoyang
District, Beijing. Groundwater at the site was contaminated by dissolved-phase petroleum hydrocarbons, including the BTEX compounds and polycyclic aromatic hydrocarbons. After 14 days, the PDB samplers were collected and the water from the PDB samplers was transferred immediately to $40-\mathrm{mL}$ amber vials for VOCs determination as described above. For comparison, groundwater samples were collected using a traditional method in triplicate.

\subsection{P\&T-GC-MS analysis}

VOC analysis was performed using an automated P\&T concentrator (Tekmar, USA) coupled to an Agilent 7890A gas chromatograph (GC) equipped with a Agilent 5975C spectrometer (MS) detector. The P\&T concentrator was equipped with a Tenax ${ }^{\circledR}$ cartridge for trapping VOCs. The water sample was purged with a stream of high-purity $\mathrm{N}_{2}$ gas at $40 \mathrm{~mL} / \mathrm{min}$ for $11 \mathrm{~min}$ at ambient temperature. After sample loading, the trapped sample components were desorbed by heating the Tenax cartridges at $250^{\circ} \mathrm{C}$ with a He gas flow at $5 \mathrm{~mL} / \mathrm{min}$ for $2 \mathrm{~min}$. After desorption, the Tenax cartridge was baked at $200^{\circ} \mathrm{C}$ for $2 \mathrm{~min}$.

The GC was equipped with a DB-624 fused-silica capillary column (J\&W Scientific, Folsom, USA; $30 \mathrm{~m} \times$ $0.25 \mathrm{~mm}, 1.4 \mu \mathrm{m}$ film thickness). The oven temperature was initially held at $35^{\circ} \mathrm{C}$ for $2 \mathrm{~min}$, increased to $180^{\circ} \mathrm{C}$ at a rate of $4^{\circ} \mathrm{C} / \mathrm{min}$ and held for $3 \mathrm{~min}$. Electron ionization was carried out at $70 \mathrm{eV}$. The temperature of the ion source and the interface of $\mathrm{P} \& \mathrm{~T}$ concentrator to GC temperature were set at 230 and $280^{\circ} \mathrm{C}$, respectively. Helium was used as carrier gas at a flow rate of $1.0 \mathrm{~mL} / \mathrm{min}$. The selected-ion monitoring (SIM) mode was employed for the quantification of VOCs. The retention time and specific ion $\mathrm{m} / \mathrm{z}$ ratio of each compound are shown in Table 1.

Table 1 also lists the linear range, regression coefficient $(R)$, and limits of detection (LOD, $\mathrm{S} / \mathrm{N}=3$ ) of the developed P\&T-GC-MS method, which were determined using spiked ultrapure water. For the method detection limit (MDL), a good precision was obtained, where the overall value was between $2 \%$ and $6 \%$ variation, and in only one case, a $12 \%$ variation was found, which was considered acceptable. Quantification was performed using fluorobenzene as internal standard.

\subsection{Data process}

To estimate the equilibration time of the VOCs, the experimental data were fitted to Eq. (1) modified from a model of Divine et al. (2005) using Graphpad Prism (ver. 4.1, GraphPad Software, San Diego, CA, USA):

$C_{\mathrm{s}}(t)=C_{\mathrm{s}, \mathrm{e}}\left(1-\exp \left(-\left(D_{\mathrm{m}} \times A \times t\right) /\left(V_{\mathrm{s}} \times L_{\mathrm{m}}\right)\right)\right)$

where, $C_{\mathrm{s}}(t)\left(\mathrm{g} / \mathrm{cm}^{3}\right)$ is the VOC concentration in the sampler at time $t, C_{\mathrm{s}, \mathrm{e}}\left(\mathrm{g} / \mathrm{cm}^{3}\right)$ is the VOC concentration in the sampler at equilibrium, $D_{\mathrm{m}}\left(\mathrm{cm}^{2} / \mathrm{sec}\right)$ is the VOC diffusion coefficient in the LDPE membrane, $A$ is the area 
Table 1 Quantitation ion and retention time for the GC-MS determination of the studied 13 VOCs, and the linear range, regression coefficient $\left(R^{2}\right)$, limits of detection (LOD) of the developed P\&T-GC-MS method

\begin{tabular}{|c|c|c|c|c|c|}
\hline Compound & $\begin{array}{l}\text { Retention } \\
\text { time (min) }\end{array}$ & $\begin{array}{l}\text { Fragment } \\
\text { masses }(m / z)\end{array}$ & $\begin{array}{l}\text { Linear range } \\
(\mu \mathrm{g} / \mathrm{L})\end{array}$ & $R^{2}$ & $\begin{array}{l}\text { LOD } \\
(\mu \mathrm{g} / \mathrm{L})\end{array}$ \\
\hline Benzene & 7.43 & 78 & $10-200$ & 0.996 & 2.9 \\
\hline Toluene & 11.63 & 91,92 & $15-200$ & 0.995 & 4.5 \\
\hline Ethylbenzene & 15.84 & 91,106 & $15-200$ & 0.994 & 4.5 \\
\hline$m$-Xylene & 16.21 & 91,106 & $17-200$ & 0.993 & 5.1 \\
\hline Styrene & 17.48 & 78,104 & $15-200$ & 0.990 & 4.6 \\
\hline Bromobenzene & 19.44 & $77,156,158$ & $15-200$ & 0.992 & 4.1 \\
\hline $1,3,5$-Trimethylbenzene & 20.63 & 105,120 & $15-200$ & 0.989 & 4.6 \\
\hline $1,2,4$-Trimethylbenzene & 21.85 & 105,120 & $26-200$ & 0.980 & 7.8 \\
\hline$p$-Isopropyltoluene & 22.99 & $91,119,134$ & $19-200$ & 0.987 & 5.6 \\
\hline$n$-Butylbenzene & 24.41 & $91,92,134$ & 19-200 & 0.986 & 5.8 \\
\hline 1,2,4-Trichlorobenzene & 29.93 & $145,180,182$ & $27-200$ & 0.960 & 8.1 \\
\hline Napthalene & 30.75 & 128 & $33-200$ & 0.948 & 10 \\
\hline 1,2,3-Trichlorobenzene & 31.64 & $145,180,182$ & $27-200$ & 0.963 & 8.1 \\
\hline
\end{tabular}

of the sampling bag exposed to water $\left(75 \mathrm{~cm}^{2}\right.$ in this study), $t$ (sec) is the time of sampling, $V_{\mathrm{s}}$ is the internal volume of the sampler $\left(20 \mathrm{~cm}^{3}\right.$ in this study), and $L_{\mathrm{m}}$ is the LDPE membrane wall thickness $(0.0001 \mathrm{~cm}$ in this study). Here, it is crucial to note that the mathematical model presented above assumes that solute diffusion through the LDPE membrane is the rate-limiting step for uptake of VOCs to the sampler.

The $D_{\mathrm{m}}$ values obtained from Eq. (1) were adopted to estimate the time required to reach $90 \%$ equilibration of sampling $\left(t_{90 \%}\right)$ by Eq. (2) (Liu et al., 2006).

$t_{90 \%}=\ln (0.10) /\left(-D_{\mathrm{m}}\right)$

The partition coefficients $(P)$ of VOCs between the PDB sampler and the groundwater were calculated based on Eq. (3).

$P=C_{\mathrm{s}, \mathrm{e}} / C_{\mathrm{w}}$

where, $C_{\mathrm{w}}\left(\mathrm{g} / \mathrm{cm}^{3}\right)$ is the VOC concentration in groundwater. $C_{\mathrm{s}, \mathrm{e}}\left(\mathrm{g} / \mathrm{cm}^{3}\right)$ can be obtained from Eq. (1) or by determining the VOC concentration in the PDB sampler after equilibrium sampling.

The $P$ values at various environmentally relevant conditions such as sample $\mathrm{pH}$, salinity and temperature can be determined in the laboratory. Therefore, by deploying PDB samplers in the field and measuring the VOC concentrations in the PDB sampler $\left(C_{\mathrm{s}, \mathrm{e}}\right)$ after equilibrium sampling in the field, the VOC concentration in groundwater $\left(C_{\mathrm{w}}\right)$ can be calculated from Eq. (3).

\section{Results and discussion}

\subsection{Effects of environmentally relevant conditions on the PDB sampling}

Figure 1 shows the uptake profiles of the studied VOCs over 14 days. The experimental data were fitted to Eq.

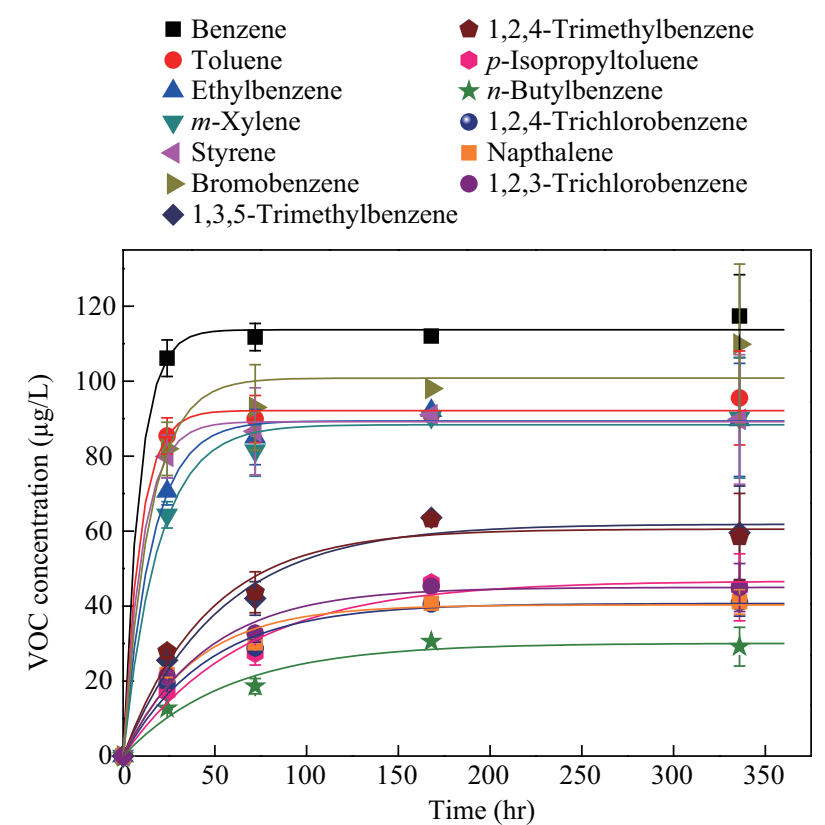

Fig. 1 Uptake profiles of the VOCs under laboratory conditions. The $1000 \mathrm{~mL}$ of pure water spiked with $100 \mu \mathrm{g} / \mathrm{L}$ each of the VOCs was sampled with $\mathrm{PDB}$ at $20^{\circ} \mathrm{C}$.

(1) to estimate the equilibration times of the VOCs. Table 2 shows the measured diffusion coefficient $\left(D_{\mathrm{m}}\right)$ and equilibration time $\left(t_{90 \%}\right)$ under different environmentally relevant sampling conditions. For VOC samples prepared in pure water, the $D_{\mathrm{m}}$ values of VOCs ranged from 1.1 $\times 10^{-10}$ to $8.3 \times 10^{-10} \mathrm{~cm}^{2} / \mathrm{sec}$ under static sampling at $20^{\circ} \mathrm{C}$, and the estimated equilibration times were in the range of 20-153 hr. The $D_{\mathrm{m}}$ value is compound dependent. While isopropyltoluene had the smallest membrane diffusion coefficient and longest equilibration time (153 $\mathrm{hr}$ ), benzene had the largest membrane diffusion coefficient and the shortest equilibration time $(20 \mathrm{hr})$. When the water sample was shaken at $200 \mathrm{r} / \mathrm{min}$, however, the equilibration time for all VOCs was significantly reduced with values ranging from 2.33 to $8.86 \mathrm{hr}$. The reduced equilibration time can be attributed to the accelerated diffusion velocity 
Table 2 Measured diffusion coefficient $\left(D_{\mathrm{m}}\right)$, equilibrium concentrations in the PDB sampler $\left(C_{\mathrm{s}, \mathrm{e}}\right)$, and equilibration time $\left(t_{90 \%}\right)$ under different environmentally relevant conditions

\begin{tabular}{|c|c|c|c|c|c|c|c|c|c|c|}
\hline \multirow{2}{*}{ Compound } & \multicolumn{3}{|c|}{$\begin{array}{c}\text { VOC sample prepared } \\
\text { in pure water, static, } 20^{\circ} \mathrm{C}\end{array}$} & \multicolumn{3}{|c|}{$\begin{array}{c}\text { VOC sample prepared } \\
\text { in pure water, shaking, } 20^{\circ} \mathrm{C}\end{array}$} & \multicolumn{3}{|c|}{$\begin{array}{c}\text { VOC sample prepared } \\
\text { in } 500 \mathrm{mmol} / \mathrm{L} \mathrm{NaCl} \text {, static, } 20^{\circ} \mathrm{C}\end{array}$} & \multirow{2}{*}{$\begin{array}{l}P(\mathrm{VOCs} \text { in } \\
\text { pure water, } \\
\left.\text { static, } 20^{\circ} \mathrm{C}\right)\end{array}$} \\
\hline & $\begin{array}{l}D_{\mathrm{m}}\left(\times 10^{10}\right. \\
\left.\mathrm{cm}^{2} / \mathrm{sec}\right)\end{array}$ & $\begin{array}{l}C_{\mathrm{s}, \mathrm{e}} \\
(\mu \mathrm{g} / \mathrm{L})\end{array}$ & $\begin{array}{l}t_{90 \%} \\
(\mathrm{hr})\end{array}$ & $\begin{array}{l}D_{\mathrm{m}}\left(\times 10^{10}\right. \\
\left.\mathrm{cm}^{2} / \mathrm{sec}\right)\end{array}$ & $\begin{array}{l}C_{\mathrm{s}, \mathrm{e}} \\
(\mu \mathrm{g} / \mathrm{L})\end{array}$ & $\begin{array}{l}t_{90 \%} \\
(\mathrm{hr})\end{array}$ & $\begin{array}{l}D_{\mathrm{m}}\left(\times 10^{10}\right. \\
\left.\mathrm{cm}^{2} / \mathrm{sec}\right)\end{array}$ & $\begin{array}{l}C_{\mathrm{s}, \mathrm{e}} \\
(\mu \mathrm{g} / \mathrm{L})\end{array}$ & $\begin{array}{l}t_{90 \%} \\
(\mathrm{hr})\end{array}$ & \\
\hline Benzene & 8.34 & 113.7 & 20.45 & 2.84 & 111.9 & 6.01 & 4.02 & 176.0 & 42.45 & 0.96 \\
\hline Toluene & 8.04 & 92.15 & 21.20 & 7.31 & 94.09 & 2.33 & 3.58 & 154.1 & 47.68 & 0.97 \\
\hline Ethylbenzene & 4.74 & 89.39 & 35.99 & 6.09 & 86.12 & 2.80 & 2.70 & 151.2 & 63.15 & 1.00 \\
\hline$m$-Xylene & 3.87 & 88.37 & 44.09 & 5.31 & 85.19 & 3.21 & 2.35 & 151.4 & 72.68 & 0.99 \\
\hline Styrene & 6.96 & 89.19 & 24.51 & 7.48 & 82.05 & 2.28 & 3.30 & 146.3 & 51.70 & 0.98 \\
\hline Bromobenzene & 5.05 & 100.8 & 33.79 & 6.25 & 103.5 & 2.73 & 2.82 & 162.5 & 60.51 & 0.97 \\
\hline $1,3,5$-Trimethylbenzene & 1.40 & 61.86 & 121.6 & 2.41 & 58.35 & 7.07 & 1.30 & 104.3 & 131.2 & 1.06 \\
\hline 1,2,4-Trimethylbenzene & 1.62 & 60.54 & 105.5 & 2.74 & 46.31 & 6.22 & 1.61 & 96.80 & 105.7 & 1.08 \\
\hline$p$-Isopropyltoluene & 1.12 & 46.73 & 152.6 & 1.93 & 40.37 & 8.86 & 1.15 & 73.02 & 148.7 & 1.10 \\
\hline$n$-Butylbenzene & 1.28 & 30.09 & 133.0 & 2.37 & 23.03 & 7.19 & 1.42 & 42.46 & 119.8 & 1.05 \\
\hline 1,2,4-Trichlorobenzene & 1.59 & 40.69 & 107.1 & 3.12 & 33.81 & 5.46 & 1.58 & 57.73 & 107.7 & 0.98 \\
\hline Napthalene & 1.90 & 40.32 & 89.59 & 3.34 & 34.64 & 5.10 & 1.75 & 55.96 & 97.69 & 0.99 \\
\hline 1,2,3-Trichlorobenzene & 1.64 & 44.99 & 104.1 & 2.96 & 38.53 & 5.76 & 1.53 & 67.38 & 111.2 & 0.98 \\
\hline
\end{tabular}

The partition coefficients $(P)$ of VOCs between the PDB sampler and water sample under laboratory conditions.

of VOCs from the surrounding media across the sampler membrane. Nevertheless, results shown in Table 2 indicated that the equilibrium concentrations of VOCs in the PDB sampler $\left(C_{\mathrm{s}, \mathrm{e}}\right)$ were less affected whether under static or shaking conditions, as compared to the variation of equilibration time under different conditions. These results suggest that when field sampling was conducted, the moving of groundwater under complicated geological conditions might reduce the equilibration time, but should not influence the equilibrium concentrations of VOCs in the PDB sampler. It is noteworthy that for the hydrophobic VOCs, however, the estimated values of $C_{\mathrm{s}, \mathrm{e}}$, in the range of $25-60 \mu \mathrm{g} / \mathrm{L}$, were significantly lower than those under spiked concentration (approximately $100 \mu \mathrm{g} / \mathrm{L}$ for each compound), which was attributed to the adsorption of these VOCs to the LDPE membrane used to prepare the PDB sampler, which reduced the VOC concentrations in the aqueous phase. The adsorption of hydrophobic VOCs to the LDPE membrane was confirmed by their detection in the $n$-hexane that was used to extract the LDPE membrane of the PDB sampler (Lohmann, 2012).

To evaluate the effects of salts in groundwater on the $C_{\mathrm{s}, \mathrm{e}}$ and $t_{90 \%}$ of PDB sampling. VOC samples prepared in $500 \mathrm{mmo} / \mathrm{L} \mathrm{NaCl}$ solution (corresponding to sea water) were sampled under static conditions at $20^{\circ} \mathrm{C}$ with the PDB sampler. Results shown in Table 2 demonstrate that in comparison with the samples prepared with pure water, the $C_{\mathrm{s}, \mathrm{e}}$ increased by $38.8 \%$ to $71.3 \%$ for all VOCs tested in the study, while the $t_{90 \%}$ of all but isopropyltoluene and butylbenzene increased by $0.2 \%$ to $124.9 \%$. The increase in $C_{\mathrm{s}, \mathrm{e}}$ was attributed to the "salting-out" effect of nonpolar organic compounds, i.e. organic compounds are generally less soluble in aqueous salt solutions than in pure water. Given that the VOCs are non-polar, the pure waterfilled PDB sampler, to some degree, can be expected to act as a concentrator for VOCs in aqueous salt solutions. Since the salinity of groundwater is generally much less than
$500 \mathrm{mmo} / \mathrm{L} \mathrm{NaCl}$, the $C_{\mathrm{s}, \mathrm{e}}$ for most groundwater should be close to that for pure water, and the $C_{\mathrm{s}, \mathrm{e}}$ measured in pure water can be used to calculate the $P$ values for VOCs in real groundwater.

Another factor that might affect the $C_{\mathrm{s}, \mathrm{e}}$ and $t_{90 \%}$ of PDB sampling is the water temperature. However, a previous study (Vroblesky and Campbell, 2001) showed that equilibration time for PDB sampling under cold conditions has no significant difference compared to warm conditions, and the differences in equilibration time due to temperature effects seem to be small for many VOCs after 7 days and for most tested compounds by 14 days. In this study, we use a sampling time of at least 14 days without further studying the effect of temperature.

\subsection{Measuring the partition coefficients of VOCs be- tween the PDB sampler and water sample}

Figure 2 shows the measured VOC concentrations in the sampler and those in the water outside the sampler after

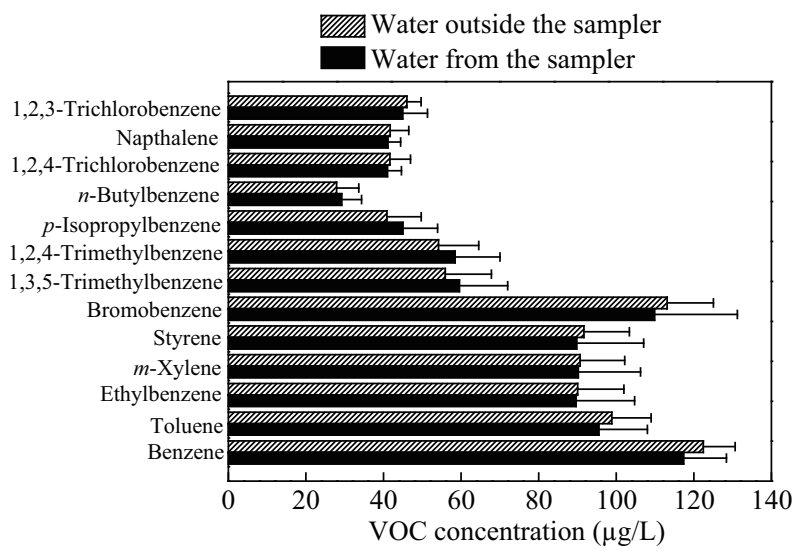

Fig. 2 Laboratory comparison of VOC concentrations in water from passive diffusion bag samplers to water outside the PDB samplers. The $1000 \mathrm{~mL}$ of pure water spiked with $100 \mu \mathrm{g} / \mathrm{L}$ each of the VOCs was sampled with PDB at $15^{\circ} \mathrm{C}$ for 14 days. 

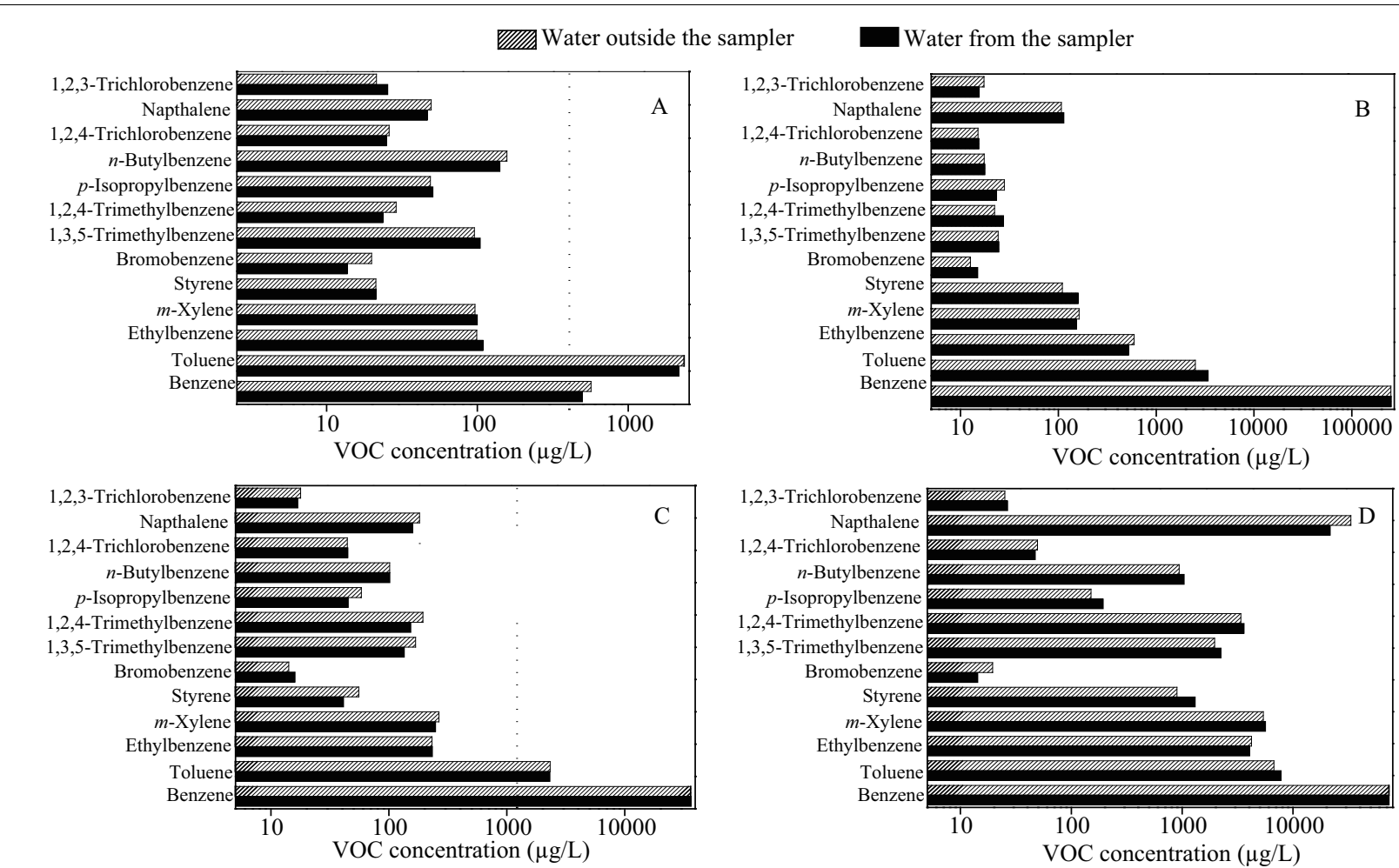

Fig. 3 VOC concentrations in water from the PDB samplers and in water outside the PDB determined after sampling 14 days in the four monitoring wells (A, B, C, D).

equilibrating for 14 days at $15^{\circ} \mathrm{C}$. There was no significant difference found using ANOVA analysis between VOC concentrations in water outside the PDB sampler and those in the PDB sampler, indicating that sampling equilibrium was reached in 14 days. The partition coefficients $P$ of VOCs between the PDB sampler and water sample, calculated by the ratio of VOC concentrations in the PDB sampler to that in water outside the PDB sampler, were between 0.96 to 1.10 (Table 2). Therefore, the measured VOC concentration in the PDB sampler can be regarded as that in the groundwater after sampling equilibrium, and no further calibration is needed.

Figure 2 also shows that for the low hydrophobic VOCs including benzene, toluene, ethylbenzene, $m$ xylene, styrene and bromobenzene, the measured $C_{\mathrm{s}, \mathrm{e}}$ and $C_{\mathrm{w}, \mathrm{e}}$ were in the range of $91-117 \mu \mathrm{g} / \mathrm{L}$, which agreed with the spiked concentration $(100 \mu \mathrm{g} / \mathrm{L})$. For the other 7 more hydrophobic VOCs, however, the measured $C_{\mathrm{s}, \mathrm{e}}$ and $C_{\mathrm{w}, \mathrm{e}}$ were significantly lower than the spiked concentrations, which was attributed to the adsorption of these VOCs onto the LDPE membrane used to prepare the PDB sampler, which reduced the VOCs in the aqueous phase.

\subsection{Determination of VOCs in the industrial contami- nation site}

The developed PDB samplers were installed in monitoring wells at four sites to measure the VOC concentrations, located along the central parallel axis. To further demonstrate the applicability of the homemade PDB sampler for field sampling of VOCs in groundwater, both the VOC concentrations in the PDB sampler and those in water outside the PDB sampler were determined after sampling 14 days. Results shown in Fig. 3 indicate that for all the 13 studied VOCs, there was no significant difference between concentrations in water from the diffusion samplers and outside the diffusion samplers collected using the traditional pump-and-sample method, demonstrating that sampling equilibration was reached in 14 days and the results from the PDB sampler were reliable.

It is evident from our field trial that all 13 VOCs were detected in the four monitoring wells (well A to D). All wells contained high concentrations of benzene (from 566 $\mu \mathrm{g} / \mathrm{L}$ in well A to over $74,000 \mu \mathrm{g} / \mathrm{L}$ in well D) and toluene (from approximately $2400 \mu \mathrm{g} / \mathrm{L}$ in well A, B, C to over $6000 \mu \mathrm{g} / \mathrm{L}$ in well D). In addition, ethylbenzene displayed mid-range concentrations from $98 \mu \mathrm{g} / \mathrm{L}$ in well A to 4200 $\mu \mathrm{g} / \mathrm{L}$ in well D.

\section{Conclusions}

A homemade PDB sampler was evaluated for the determination of VOCs in industrial contamination sites. Environmentally relevant sampling conditions such as salinity, agitation and temperature can influence the sampling equilibration time, but generally sampling equilibration can be reached in 14 days under real field sampling of VOCs in groundwater. Field testing in a contaminated site showed that the VOC concentrations in the devel- 
oped sampler were equal to those in the ground water at equilibrium, thus the homemade PDB samplers offer an inexpensive alternative method for routine monitoring of VOCs in groundwater in wells.

\section{Acknowledgments}

This work was supported by the China National Special Research Fund for Non-Profit Sector of Environmental Protection (No. 201009015), and the National Science Fund for Distinguished Young Scholars (No. 21025729).

\section{References}

Divine C E, Madsen L L, Andrews S D, Santangelo-Dreiling T, 2005. Passive diffusion ground water samplers at a site with heterogeneous hydrostratigraphy: Pilot study results. Ground Water Monitoring and Remediation, 25(1): 90-99.

Ehlke T A, Imbrigiotta T E, Dale J M, 2004. Laboratory comparison of polyethylene and dialysis membrane diffusion samplers. Ground Water Monitoring and Remediation, 24(1): 53-59.

Harter T, Talozi S, 2004. Evaluation of a simple, inexpensive dialysis sampler for small diameter monitoring wells. Ground Water Monitoring and Remediation, 24(4): 97-105.

Liu J F, Hu X L, Peng J F, Jönsson J Å, Mayer P, Jiang G B, 2006. Equilibrium sampling of freely dissolved alkylphenols into a thin film of 1-octanol supported on a hollow fiber membrane. Analytical Chemistry, 78(24): 8526-8534.

Lohmann R, 2012. Critical review of low-density polyethylene's partitioning and diffusion coefficients for trace organic contaminants and implications for its use as a passive sampler. Environmental Science and Technology, 46(2): 606-618.

Martin H, Patterson B M, Davis G B, 2003. Field trial of contaminant groundwater monitoring: comparing time-integrating Ceramic dosimeters and conventional water sampling. Environmental Science and Technology, 37(7): 1360-1364.

Mcleish K, Ryan M C, Chu A, 2007. Integrated sampling and analytical approach for common groundwater dissolved gases. Environmental Science and Technology, 41(24): 8388-8393.

Verreydt G, Bronders J, van Keer I, Diels L, Vanderauwera P, 2010. Passive samplers for monitoring VOCs in groundwater and the prospects related to mass flux measurements. Ground Water Monitoring and Remediation, 30(2): 114126.

Vroblesky D A, Campbell T R, 2001. Equilibration times, compound selectivity, and stability of diffusion samplers for collection of ground-water VOC concentrations. Advances in Environmental Research, 5(1): 1-12.

Vroblesky D A, Thomas H A, 1997. Diffusion samplers as an inexpensive approach to monitoring VOCs in ground water. Ground Water Monitoring and Remediation, 17(2): 177184. 